\title{
$\mathrm{NGS}$ 기반 밀양 23 호/기호벼 재조합자식 유전집단(MGRIL)을 이용한 CAPS 마커 개발 및 줄기 굵기 형질 관련 $\mathrm{QTL}$ 분석
}

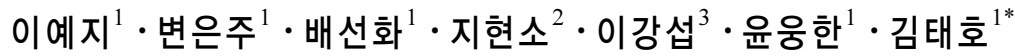 \\ ${ }^{1}$ 농촌진흥청 국립농업과학원 유전체과, ${ }^{2}$ 농촌진흥청 국립농업과학원 유전자공학과, \\ ${ }^{3}$ 농촌진흥청 국립농업과학원 생물안전성과
}

\section{Development of NGS-based New CAPS Markers and QTL Analysis of Stem Diameter using Milyang23/Gihobyeo Recombinant Inbred Lines (MGRIL)}

\author{
Ye-Ji Lee ${ }^{1}$, Eun-Ju Byeon ${ }^{1}$, Seon-Hwa Bae ${ }^{1}$, Hyeonso $\mathrm{Ji}^{2}$, \\ Gang-Seob Lee ${ }^{3}$, Ung-Han Yoon ${ }^{1}$, and Tae-Ho Kim ${ }^{1 *}$ \\ ${ }^{I}$ Genomics Division, National Institute of Agricultural Sciences, RDA, Jeonju, 54874, Korea \\ ${ }^{2}$ Genetic engineering Division, National Institute of Agricultural Sciences, RDA, Jeonju, 54874, Korea \\ ${ }^{3}$ Biosafety Division, National Institute of Agricultural Sciences, RDA, Jeonju, 54874, Korea
}

\begin{abstract}
The rice recombinant inbred lines derived from Milyang23 and Gihobyeo cross were used in genetic mapping and QTL analysis studies. In this study, we developed a new 101 CAPS markers based on the SNPs in the whole genome region between these varieties. As a result, the total genetic distance and average distances were 1,696.97 cM and $3.64 \mathrm{cM}$, respectively. In comparison to the distance of the previous genetic map constructed based on 365 DNA markers, the new genetic map was found to have a decreased distance. The map was applied for the detection of QTLs on all seven traits relevant to diameter of stem internode, length of culms, length of panicles and the number of panicles including the correlation analysis between each trait. The QTLs results were similar to the report in previous studies, whereas the distance between the markers was narrowed and accuracy increased with the addition of 101 CAPS markers. A total of 9 new QTLs were detected for stem internode traits. Among them, qI1D-6 had higher LOD of 5.1 and phenotype variation of $50.92 \%$. In this experiment, a molecular map was constructed with CAPS markers using next generation sequencing showing high accuracy for markers and QTLs. In the future, developing more accurate QTL information on stem internode diameters with various agriculturally important traits will be possible for further rice breeding.
\end{abstract}

Keywords : Molecular genetic map, CAPS markers, Stem diameter, QTLs, Rice

\section{서 언}

작물의 유전체에서 분자 마커(molecular marker)는 어떤 특정 한 위치나 지역을 탐색하고, 농업적으로 유용한 형질들을 탐색하 거나, 육종 시 개체를 선발하는데 가장 중요한 의미를 가진다 (McCouch et al. 2002). 지금까지 restriction fragment length polymorphism(RFLP), amplified fragment length

*Corresponding author (E-mail: thkim@rda.go.kr, +82-63-238-

4563 E-mail: Fax: +82-63-238-4554)

(Received on June 1, 2016. Accepted on July 22, 2016.)
polymorphism(AFLP), simple sequence repeat(SSR), single nucleotide polymorphism(SNP) 등이 개발되어 분자육종에 보 편적으로 사용되고 있다(Cho et al. 1998b, Nasu et al. 2002). 최근 차세대 염기서열 분석방법(next generation sequencing, NGS)을 이용하여 많은 주요 작물에 대해 빠른 속도로 유전체 정보를 해독하고 있으며, 데이터를 대량으로 생산하고 있다(Huq et al. 2016). 마커 생산이 제한되어 있던 과거에 비해 빠른 시간에 대량의 SNP 마커를 생산할 수 있게 되었고, 표현형 데이 터와 연계함으로써 실제 육종 현장에서 농업적으로 활용 가능한 정보를 만들어 준다. 
분자 마커를 이용하여 유전체에서 그 마커들 간의 또는 발현유 전자와 마커들 간의 거리를 교배 집단 내 재조합 비율을 바탕으로 상대적 거리를 나타내어 분자유전지도를 작성하고, 육종 시 선발 마커를 개발하는데 적극 활용하였다(Ji et al. 2012). 벼에서는 135 개 RFLP 마커를 이용하여 최초로 유전지도가 작성되었으며 (McCouch et al. 1988), 이후 자포니카 품종인 Nipponbare와 인디카 품종인 Kasalath 집단에서 2,275개의 RFLP 마커를 이용 한 고밀도 유전지도가 작성된 바 있었다(Harushima et al. 1998).

한편, 밀양 23 호와 기호벼의 재조합 자식계통집단에 대해 RFLP 마커(Cho et al. 1998a), AFLP 및 SSR 마커(Cho et al. 1998b), PCR 기반의 sequence tagging site(STS), insertion and deletion(InDel), SSR 마커(Ji et al. 2012) 그리고 SNP 기반 cleaved amplified polymorphism sequence(CAPS) 마커 (Lee et al. 2014)를 이용한 유전지도가 작성되었으며, 이들 중 초창기 분자 마커를 기반으로 하여 수량관련 형질, 품질 관련 특성, 유묘 내염성 등의 quantitative trait loci(QTL)이 보고된 바 있다(Kang et al. 1998, Kang et al. 1999a, Kang et al. 1999b, Kwak et al. 2004, Kwak et al. 2005).

다양한 벼의 주요 형질 중에 하나인 줄기 굵기는 벼의 수량을 결정하는 중요한 요인으로써, 생산성과 관련이 있다. 너무 가늘 거나 적정 경도를 가지지 못한 줄기는 도복에 약하고, 이로 인해 양분이동의 억제와 동화작용에 장애가 생겨 쌀의 품질이 떨어지 게 된다(Kashiwagi \& Ishimaru 2004, Kashiwagi et al. 2008, Lee et al. 2014, Ookawa et al. 2010). 또한, 반왜성 단간유전자 로 알려진 $s d-1$ (Cho et al. 1994)를 비롯한 관련 유전자와 QTL을 활용하여 벼의 우수한 품종을 육성하고 생산량을 증대시킬 수 있지만(Asano et al. 2007) 이에 대한 연구가 더 필요한 실정이다 (Lee et al. 2014).

본 연구에서는 차세대 염기서열 분석방법을 통해 밀양 23 호와 기호벼 사이의 특이적인 SNP을 탐색하여 CAPS 마커로 개발한 후, PCR 기반 마커들로 구성된 밀양 23 호와 기호벼의 재조합 자식 계통집단(Milyang23/Gihobyeo Recombinant Inbred Lines, MGRIL)의 유전지도(Ji et al. 2012, Lee et al. 2014)와 통합하여 보다 정밀한 분자유전지도를 작성하였다. 또한, 분자유전지도를 기반으로 줄기 굵기 형질에 관한 새로운 QTL을 탐색하였고, 동시 에 벼의 간장, 수장, 수수에 대한 QTL 분석도 실시하였다.

\section{재료 및 방법}

\section{벼(Oryza sativa L.)의 유전집단 육성 및 DNA 추출}

본 실험은 우리나라에서 육성한 인디카 통일형 품종인 밀양 23 호를 모본으로 하고, 자포니카 품종인 기호벼를 부본으로 하여 육성한 MGRIL을 유전분석 집단으로 사용하였다. 이 유전집단 은 1998년도에 부모친이 교배되었으며, $\mathrm{F}_{2}$ 를 자식하여 얻은 종자를 매년 2회씩 single seed descent(SSD)법으로 $\mathrm{F}_{6}$ 세대까지 육성하였다. 그 후, $\mathrm{F}_{7}$ 세대부터는 계통당 일렬 재배하여 일계통 일종자법을 통해 23 세대 이상 162 계통으로 형질이 고정된 집단 이다.

MGRIL 집단을 각 계통 별로 20개체씩 파종 후 약 1 개월 지난 식물의 잎을 채취하였다. 잎은 액체질소에 냉각시킨 상태에 서 막자 사발을 이용하여 분말상태로 마쇄하였다. DNA 추출은 Qiagen사의 Qiagen DNeasy Plant Maxi Kit를 이용하여 제공된 매뉴얼을 따라 수행하였다.

\section{NGS를 이용한 대량 염기서열 분석}

밀양 23 호와 기호벼의 잎을 이용하여 추출된 $\mathrm{DNA}$ 는 차세대 염기서열 분석에 사용하였다. 두 모본의 재염기서열(re-sequenc ing) 분석을 위해 Illumina HiSeq 2000 플랫폼을 이용하여 paire d-end sequencing을 수행하였다. 리드(read)의 길이는 $101 \mathrm{bp}$ 로 생성되었으며, 염기서열의 변이 분석을 위해서 리드는 $1 \%$ 미만 의 오류율을 갖는 Phred Quality Value $\geq$ Q20(ASCII Characte r Code +33$)$ 을 사용하였다. 전체 염기서열이 밝혀져 있는 벼의 표준유전체(reference sequence)는 Oryza sativa L. cv. Nipponb are(MSU Rice Genome Annotation Project, Pseudomolecules Build 7.0)이며, 유전체 구조를 분석하기 위한 주석(annotation) 정보는 RAP-DB(http://rapdb.dna.affrc.go.jp/)을 이용하였다. 정확하고 고품질의 서열을 얻기 위해서 낮은 리드들을 제거하는 작업을 수행하였으며, 선별된 리드들을 이용하여 Nipponbare에 각각의 염색체로 mapping 하였다. 밀양 23 호와 기호벼의 염기서 열은 CLC Assembly Cell(ver. 3.3.2, http://www.clcbio.com) 을 이용하여 표준유전체에 조립(assembly)한 후, 변이를 분석하 였다(Jeong et al. 2013).

\section{SNP 프라이머 제작}

차세대 염기서열 분석방법으로 해독된 양친의 유전체 염기서 열에서 5' untranslated region(5'UTR), 3' untranslated region(3'UTR), intron, coding sequence(CDS)에 존재하는 
genic과 두 genic 사이에 위치하는 intergenic을 포함한 전체 영역에서 SNP을 선발하였으며, 두 품종 사이에서 4 개 $(E c o R$ I, HindIII, Pst I, Xho I )의 제한효소자리에 위치하고 특이적으 로 나타나는 SNP을 후보 CAPS 마커로 선발하였다. 제한효소 인식부위는 특이성과 관련하여 palindromic 구조로 이루어진 6 개의 염기를 인식하는 제한효소를 이용하였으며, 이후 선별한 $\mathrm{SNP}$ 을 기준으로 Vector NTI 9.0.0 프로그램을 활용하여 프라이 머를 제작하였다. 프라이머 설계 시, 온도는 $58 \sim 62^{\circ} \mathrm{C}$, 길이는 $20 \sim 25 \mathrm{bp}, \mathrm{GC}$ 함량은 $40 \sim 60 \%$ 으로 설정하였다.

\section{CAPS 마커 개발 및 유전형 분석}

CAPS 마커의 유전형을 분석하기 위해 앞서 설계한 프라이머 로 PCR을 수행하였다. PCR 반응을 위해서 반응액의 총 부피는 $20 \mu 1$ 로 하였으며, 희석된 각 $10 \mathrm{pmol}$ 의 프라이머, $10 \mathrm{X} \mathrm{Taq}$ Buffer $2 \mu \mathrm{l}$, dNTP 10Mm 0.4 $\mathrm{ll}$, Taq polymerase 0.5 unit, $\mathrm{gDNA}$ 를 사용하였다. $\mathrm{PCR}$ 증폭조건은 $95^{\circ} \mathrm{C}$ 에서 3 분간 pre-denaturation 시키고, $95^{\circ} \mathrm{C}$ 에서 40 초간 denaturation, 58 7 $0^{\circ} \mathrm{C}$ 에서 40 초간 annealing, $72^{\circ} \mathrm{C}$ 에서 1 분 30 초간 34 회 반복하 여 polymerization을 한 다음 마지막으로 $72^{\circ} \mathrm{C}$ 에서 7 분간 유지 하였다.

제한효소 처리는 총 $10 \mu \mathrm{l}$ 으로 하고 $5 \mu \mathrm{PCR}$ 산물, $1 \mu \mathrm{l} 10 \mathrm{X}$ Buffer와 5U restriction endonuclease를 $37^{\circ} \mathrm{C}$ 에서 3 시간 이상 처리하였다. 제한효소 처리 후, $1 \%$ 아가로스 젤에 $150 \mathrm{~V}$ 로 1 시간 30 분 동안 전기영동 하였다. 처음에는 모본간 다형성을 검정한 뒤, 선별된 CAPS 마커들로 MGRIL 집단의 유전형 분석을 실시 하였다.

\section{물리 및 유전지도 작성}

MGRIL 집단의 물리 및 유전지도 작성을 위해서 Lee et al. (2014) 연구에서 보고된 365개의 마커와 본 연구에서 새로 개발 한 CAPS 마커를 사용하였다. 이후, DNA 마커의 염기서열 및 위치 정보를 이용하여 벼 유전체상에서의 위치를 파악한 다음, Nipponbare(build 7.0) 위치정보를 사용하여 물리지도를 작성 하였다. 이를 위해 CAPS 마커는 SNP의 위치, InDel, SSR, STS 마커는 프라이머의 중간 값을 이용하여 각 염색체 별 마커의 위치를 표시하였다.

유전지도 작성을 위해서 MapDisto 1.7.7.0.1.1(XL2010) 프 로그램(Lorieux 2012)을 이용하여 MGRIL 집단의 유전형을 분석하였다. 각 계통들의 SNP은 homozygous한 밀양23호와 기호벼의 $\mathrm{SNP}$ 을 각각 $\mathrm{A}$ 와 $\mathrm{B}$, heterozygous를 $\mathrm{H}$ 로 나타내어
부, 모친의 유전형 수치로 전환하였으며, 누락된 데이터는 Nㅡ으로 표시하였다. 유전지도는 MGRIL 집단의 유전형을 입력한 후, "Draw all sequence" 메뉴로 각 연관 군에 있는 마커들 간의 유전거리를 산출하였고, 각각의 마커와 연관성을 나타내는 Kosa $\mathrm{mbi}$ 함수식을 적용하였다. 최종 물리지도와 유전지도의 그래픽 레이아웃은 MapChart 프로그램(Voorrips. 2002)을 이용하였다.

\section{표현형 조사 및 QTL 분석}

밀양 23 호와 기호벼 그리고 162계통들은 한 계통 당 20 개체씩 자연 상태에서 육성하였으며, 그 중 5 개체를 선발하여 표현형 조사에 이용하였다. 표현형 조사에는 1절 줄기 굵기(first internode diameter, I1D), 2절 줄기 굵기(second internode diameter, I2D), 3 절 줄기 굵기(third internode diameter, I3D), 4절 줄기 굵기(fourth internode diameter, I4D), 간장(culm length, CL), 수장(panicle length, PL), 수수(panicle number, $\mathrm{PN})$ 를 측정하였다. 줄기 굵기는 이삭목과 첫 번째 마디 사이를 1절로 하고, 그 아래 마디를 따라 마디 사이를 각각 2절, 3절, 4절로 정하였다. 줄기 굵기는 마디 사이 중앙에서 가장 두꺼운 부분을 측정하였다.

QTL 분석은 MGRIL 집단의 유전지도와 표현형 값을 이용하 여, Windows QTL Cartographer V2.5(http://statgen.ncsu.edu/ qtlcart/WQTLCart.htm) (Wang et al. 2007) 소프트웨어로 수행 하였다. 각 형질 별 유의수준(p<0.05)으로 1,000 회의 치환을 실시하는 composite interval mapping(CIM)방법을 이용하였 으며, $95 \%$ 의 유의성 있는 logarithm of the odds(LOD)값을 채택하였다. 신뢰도가 높은 QTL을 찾기 위해 LOD 값이 3.0 이상인 것을 선택하였다.

\section{결과 및 고찰}

\section{CAPS 마커 개발}

$\mathrm{NGS}$ 를 통해 밀양 23 호와 기호벼의 유전체 서열을 분석하여 변이를 탐색하였다. 대량으로 생산된 SNP을 기반으로 Lee et al. (2014)이 선발한 후보 CAPS 마커 중에서 genic(UTR, intron, $\mathrm{CDS}$ )과 intergenic의 모든 영역에 분포하고 4 개의 제한효소 (EcoR I, HindIII, Pst I , Xho I ) 자리에 위치한 특이적인 SNP 을 후보 CAPS 마커로 개발하였다. 후보 CAPS 마커 7,843개 중 선발된 110 개를 대상으로 실험을 수행하여 두 모본의 다형성 을 검정하였다. 이와 같은 실험을 수행하여 후보 CAPS 마커 가운데 안정적으로 확인이 가능한 CAPS 마커 101 개를 개발하 
였으며(Table 1), 이는 MGRIL 집단의 유전형 분석에 사용하였 다(Fig. 1). CDS 영역의 SNP을 활용하여 제작한 CAPS 마커 (Lee et al. 2014)와 비교하였을 때, 본 연구에서 개발한 CAPS 마커들은 genic과 intergenic을 포함하는 SNP을 선정함으로써 12 개의 염색체 내에 다양한 CAPS 마커가 고루 분포하는 지도를 작성하는데 효과적이었다.

\section{물리 및 유전지도 작성}

앞서 선발된 101 개의 CAPS 마커와 Lee et al. (2014)에 의해 보고되었던 365 개 마커(36 InDel, $146 \mathrm{CAPS}, 87 \mathrm{SSR}, 88$ $\mathrm{STS}, 8 \mathrm{RTM}$ )를 통합하여 물리 및 유전지도를 작성하였다 (Table 1, Table 2, Fig. 2, Fig. 3). 표준유전체로 사용한 Nipponbare genome(build 7.0)에 총 466개 마커들의 프라이머 서열을 mapping하고 이를 벼 유전체상의 물리적 위치를 확인한 뒤 물리지도를 작성하였다. 이 물리지도에서 마커 간의 물리적 거리의 합은 $371.25 \mathrm{Mbp}$ 이었으며, 이를 총 유전거리로 나누어 구한 $1 \mathrm{cM}$ 당 평균 물리적 거리는 약 $219 \mathrm{kbp}$ 이었다. $1 \mathrm{cM}$ 당 평균 물리적 거리가 약 $230 \mathrm{kbp}$ 인 Lee et al. (2014)의 결과에
비추어 볼 때, 본 연구에서 작성된 $1 \mathrm{cM}$ 당 평균 물리적 거리의 수치는 정확도가 높다고 할 수 있다.

또한, 동일 집단을 이용하여 통합된 유전지도를 작성하였다. 총 유전거리는 $1696.97 \mathrm{cM}$ 이었으며, 마커 간의 평균 거리는 $3.64 \mathrm{cM}$ 이었다. Lee et al. (2014)가 보고한 365개의 마커를 이용한 MGRIL 집단의 유전지도에서 마커 간의 평균 거리가 $4.6 \mathrm{cM}$ 인 점을 비추어 볼 때, 빠른 시간에 효율적인 분석이 가능 한 SNP 기반 CAPS 마커의 수가 늘어남으로써 통합된 유전지도 의 마커 밀도와 정확도 또한 높아졌음을 알 수 있었다.

\section{표현형 상관관계 분석}

MGRIL 집단의 표현형 조사를 위해서 1절 줄기 굵기(I1D), 2절 줄기 굵기(I2D), 3절 줄기 굵기(I3D), 4절 줄기 굵기(I4D), 간장 $(\mathrm{CL})$, 수장 $(\mathrm{PL})$, 수수 $(\mathrm{PN})$ 를 측정하였다. 조사된 형질의 변이 분포를 나타내는 히스토그램은 연속적인 정규분포를 보였 으며, 대부분은 부모의 품종을 벗어나는 초월분리현상을 보였다 (Fig. 4). Lee et al. (2014)의 연구와 동일한 방법으로 표현형 조사에 대한 그래프를 작성한 결과, 수수를 제외한 6 가지 형질들

Table 1. The list of 101 CAPS markers.

\begin{tabular}{|c|c|c|c|c|c|c|}
\hline Chr\# & $\mathrm{M}$ & $\begin{array}{l}\text { SNP } \\
\text { Position } \\
\text { (bp) }\end{array}$ & p) & End(bp) & Forward sequence & Reverse sequence \\
\hline hr01 & RS01001 & $5,124,167$ & $5,123,926$ & $5,124,638$ & CAGTGGAAAGCTTTGGC & TCTGCGAGCGCCATAACTTTTACTA \\
\hline hr01 & RS01002 & $12,331,930$ & $12,331,621$ & $12,332,389$ & CGGTGGTCTTGACAATTTGTTGTTG & CAGGTCACACCTTGGAAGGTTAACA \\
\hline hro1 & RS01003 & 12,509 & $12,509,627$ & $12,510,378$ & ATGAAGTGCCTCCTCGTCTTCTTCC & CCTTTTGCCGAACACAGCGTCTATA \\
\hline hro1 & RS01004 & 12,635 & $12,634,873$ & $12,635,544$ & AAGAACCATTAGAATGCATGCCACA & TGCATCATGCATTTGGTCTGTAGAA \\
\hline hro1 & RS & 28,36 & 28,36 & $28,368,637$ & AATTTAGTGCAGCTGGTGCTACCCA & GAGCTGCATTGTTGTACCCATGTTG \\
\hline hro1 & $\mathrm{RS}$ & 28,490 & $28,490,570$ & $28,491,166$ & TTGCACGAATCTCAACTTACCTCCA & GGCTTGAACAGTCATCAGATTTGCA \\
\hline hro1 & RS & 29,53 & 29,531 & $29,532,070$ & TCGATGATCTTCCCGGTCACC & GAGCGCTCCССТTTCTCCAA \\
\hline hr01 & $\mathrm{RS}$ & 32,6 & 32,6 & $32,652,423$ & СTACCTTGGCTACATCGGTCATTCG & CACGCGACGCATAATCTCAGGTATT \\
\hline hr01 & RSO & 32,95 & 32,95 & $32,960,179$ & CGTATTGGGCTAGAAGAGCAAAAGG & TGGTACACTGGTGGTCCAAAATCTG \\
\hline hr01 & $\mathrm{RS} 0$ & 35,616 & $35,616,151$ & $35,616,883$ & GAAAAATTCTGACCGACAGATTCCG & TAAAAGCGGTGCGAAGCACTGTTTA \\
\hline Chr01 & RS01011 & $37,719,615$ & $37,719,316$ & $37,720,045$ & CCTGAATCTGCCACAAAAGTCCAT & CGATTTGATCTCTCCCCGTATCTTG \\
\hline hr02 & RS02001 & $5,066,630$ & $5,066,304$ & $5,067,010$ & AGAAAACTTCATTTTGATGCGGTCC & TGGTAAGCATGGCTGATGATGTTTT \\
\hline hr02 & RS02002 & $5,729,337$ & $5,729,192$ & $5,729,781$ & ICTCCACGCTA & GCACTCTTGTTGGAAGCTGTGTCAT \\
\hline hr02 & RS02003 & $5,912,101$ & $5,911,912$ & $5,912,668$ & ATGCATTTGTGAACGTACAGCATGC & AGCATGCGTTAGAAAATCAGTTCGA \\
\hline Chr02 & RS02004 & $11,699,735$ & $11,699,522$ & $11,700,042$ & AAATGTTTCCCCTTTCCGTCATTG & CATGGTGTGATGTTTGGCTATAGCG \\
\hline hr02 & 005 & 13,416 & $13,415,923$ & $13,416,762$ & ATCGCAGATGAGC & GGACATCCATTGATAAGGCAAGACA \\
\hline hr02 & RS02006 & $15,480,212$ & $15,479,981$ & $15,480,640$ & TGCATGAATCATAGGTGTGGACTGG & CTGACATTCACTTGCTCGTGAGGAT \\
\hline hr02 & RS02007 & $19,310,049$ & $19,310,244$ & $19,310,534$ & TAGTGC & A \\
\hline $\mathrm{ar} 02$ & $\mathrm{R}$ & 20,2 & 20 & 20,2 & GGG & TGCATAGCCATCTGGAACCTTTATG \\
\hline 22 & & 040 & $20,731,910$ & $20,732,486$ & ATATTTACACCCCCCGAATGTGCTT & CGCACTGTGCTTTCGATTGTGACTA \\
\hline 2 & RS020 & $23,255,6$ & $23,255,398$ & $23,256,104$ & TGTGAGCTGCAAGAATTTCCCTG & GCATCACTCCAGAATAGCTCATTGC \\
\hline Chr02 & $\mathrm{RS} 020$ & 27,328 & $27,328,2$ & $27,328,927$ & GAGATTTTGCTCAAGATAGAGGCCG & TGTGCCAAATCTTAAGCTCGTCATC \\
\hline Chr02 & RS02012 & $29,528,239$ & $29,528,008$ & $29,528,652$ & AGTGAAAGCGCAATACCTGAAAACG & AATCGCATCTGTGGAGGAGGAGTAT \\
\hline
\end{tabular}




\begin{tabular}{|c|c|c|c|c|c|c|}
\hline 2 & & & & & & \\
\hline hr02 & & & & ,066 & TCCAATGTCTGAACTCCTCAGCATG & GATTCACCGAAGAAATGCATTGTGA \\
\hline hr02 & 2015 & 33,48 & 33,4 & $33,482,305$ & ATTCAGGAGGGGAACCATATTCTGC & TTGTGCGGAGACCATTCGAAAA \\
\hline hr03 & RS03001 & $4,329,529$ & $4,329,263$ & $4,329,965$ & AGAATGAATGCCAAGAACTGCTGTG & GGAATTGCCCAGGTTCAACTACAA \\
\hline hr03 & RS03002 & $5,922,132$ & $5,921,982$ & $5,922,694$ & TACTGACCTTGGGAAATCTAGGGGA & GGTTAAAACCCTGGGTTGGACATT \\
\hline hr03 & RS03003 & $8,014,937$ & $8,014,701$ & $8,015,437$ & TCGTTGGTACCAAGGTATATGCGAG & TTCTCTTTTGCCTCATTTGCATCTG \\
\hline Chr03 & RS03004 & $8,047,437$ & $8,047,218$ & $8,047,864$ & TGGTTAATATGGCTGCTCAGGTTGG & CCAGCTGCAAATGAACTTTCACTTG \\
\hline Chr03 & RS03005 & $8,698,774$ & $8,698,573$ & $8,699,209$ & GACGCCTCCTTTTCTTTTTTTCTCC & GGAGCAACA \\
\hline Chr03 & RS03006 & $15,628,988$ & $15,628,661$ & $15,629,416$ & GGTTTCCGGGCCTCCTGAAT & TGTTGGCACACCGGCTTACATT \\
\hline Chr03 & $\mathrm{RSC}$ & 16,1 & & 3,991 & ACAGCGAAATCAGTTCTTCCTCCTC & TCAATGCAATCAGTGCCACCATAC \\
\hline Chr03 & & 16,4 & & 16,4 & TTACTGATTGGACTGCCACGTAGGA & GATCTAATCAACCCGGCAAATCAAC \\
\hline Chr04 & RS04001 & 253,652 & 253,332 & 254,084 & TAGGGTAAATCTCAGTTTTGCCCGG & GGCCATTAACCATTTCAGCTCTCTG \\
\hline Chr04 & RS04002 & $1,911,582$ & $1,911,279$ & $1,911,944$ & CCTGCTTGAGATTTA & CCAATAGTGGAGA \\
\hline Chr04 & RS04003 & $6,388,586$ & $6,388,341$ & $6,389,023$ & GTTCACTCATCAGCTCCTGATTTCG & TGTAAATGGGCTCTTGTTATGGCAG \\
\hline Chr04 & RS04004 & $8,780,603$ & $8,780,331$ & $8,780,944$ & TGACCGTACGATATCCCTGAACAGA & TGTGAGGTGACAGTGGATCTAACGG \\
\hline Chr04 & RS04005 & $17,888,887$ & 17,88 & $17,889,433$ & GAGCAGCCAAAGTCCGACACCT & GGCACGAGTTGCAATTGGTACGTA \\
\hline hr04 & & & & B,214 & CGATCTGGCGAG & CACGTCTCACGCTAGA \\
\hline hro4 & & & & 042 & ACGCAGAAACTCACAACGC & TTGCATTGATAGCTTAGCTTGCCAC \\
\hline Chr04 & & & & $31,855,747$ & GCAAGCTTGCTTCCGGTGCT & CAACCGGAAACCGAGTTGTGACTA \\
\hline hr04 & & 33,55 & & $33,596,228$ & CCTACAGCTTCGGAGTTCTC & ICTTGATTGCCAGC \\
\hline hr05 & RS05001 & $8,526,221$ & & & CTCAAA & GGA \\
\hline hr05 & RS05002 & 9,22 & & & CCTTGG & TTCG \\
\hline hr05 & & $16,287,448$ & & 755 & GGCACA & CACCTA \\
\hline hr06 & $\mathrm{RSC}$ & & & & & TGC \\
\hline Chr06 & RS06002 & & & & & CAT \\
\hline Chr06 & RSC & 4,38 & & & TGT & CTT \\
\hline Chr06 & RS06004 & $9,355,097$ & 9,35 & $9,355,701$ & TGCGG & CCATGA \\
\hline hr06 & RS0 & 24,47 & 24,4 & 24,4 & GTT & ГТТТ \\
\hline hr06 & Rs & 26, & & ,388 & СTT & ГТАС \\
\hline hr06 & $\mathrm{R}$ & & & 659 & $\mathrm{CG}$ & СACT \\
\hline hr06 & $\mathrm{RSC}$ & 29,4 & 29 & 129 & TTA & TGAC \\
\hline hr07 & RS07001 & $3,427,625$ & $3,427,391$ & $3,428,060$ & IATCAT & $\mathrm{AAC}$ \\
\hline hr07 & RS07002 & 7,13 & 7,13 & 7,13 & GGG & AGCTA \\
\hline hr07 & $\mathrm{RS}$ & 14,5 & & $14,511,489$ & GTT & ACA \\
\hline hr07 & $\mathrm{RS}$ & 17,19 & & 576 & CGCAAT & ICTTGCCACTTGCC \\
\hline hr07 & & & & 20,6 & CGGGGTG & GGGTAAGT \\
\hline hr07 & & & & 397 & CGGT & $\mathrm{sCCA}$ \\
\hline hr07 & & & & 508 & TACA & ACTT \\
\hline hr08 & $\mathrm{R}$ & & &, 410 & ATGC & TGTGC \\
\hline hr08 & 02 & 15,8 & & ,310 & AAGGGG & GCTGTGCTGGA \\
\hline Chr08 & 03 & & & $16,373,746$ & AGGAC & AGCTGC \\
\hline Chr08 & RS08004 & 16,9 & & $16,959,614$ & TAAAAACAATCCAGCAAATGGGTGC & CCTCGATTTAGACAAGCTGGAGCAA \\
\hline Chr08 & RS08 & 21,767 & 21 , & $21,768,323$ & AGCAGCAGGATATTGATCCATGAGC & TGTGAGGTTTCTGAATTCCACTCCA \\
\hline Chr09 & $\mathrm{RS} 0$ & $15,804,092$ & 15,803 & $15,804,572$ & GACGAATGGTCAAACGTTGGTTAAA & AGGCATCCAAGTCTTTTCTCCTCAA \\
\hline Chr09 & RS09002 & $18,498,864$ & 18,498 & $18,499,331$ & AAGCTTGACTGAAGACTGGATTCCC & GCAGGTTGCAATTACCAGGCATAT \\
\hline Chr09 & $\mathrm{RS} 0$ & 22,130 & 22 , & $22,131,474$ & ATCGGAAATCTCCCAAAATTGTTCC & GAAGTTTGCTATGCATGCGATGC \\
\hline Chr09 & RS09004 & $22,736,643$ & $22,736,315$ & $22,736,805$ & AAGTTGCCAGACGACATACAAGCG & TTTCCTAGCTGCCCACTGGATGTT \\
\hline Chr10 & RS10001 & 816,748 & 816,421 & 817,182 & ACCAACAGCACCGGTGTCCTAGT & TTCTTACCCTGGCATCCATCGTT \\
\hline Chr10 & RS10002 & $1,244,755$ & $1,244,417$ & $1,245,200$ & TTATCATTGAAGTTTTCGGTTGCCC & TGGTGAGATTCCAGCAGAATTTGG \\
\hline Chr10 & RS10003 & $6,692,050$ & $6,691,752$ & $6,692,464$ & TTAGAGATGGTGGGCTATTGGTTCC & ACAACAAACCCACAGCTAATCCTCC \\
\hline Chr10 & 004 & $8,322,859$ & $8,322,620$ & $8,323,299$ & TTCGTATTGCAGAGAA & TGCTCCCATATTTCTAGCCTCCTTG \\
\hline Chr10 & 05 & & 8,32 & & TACATGCCTTCTATCA & GCTCCCATATT \\
\hline & & & & & & Alc \\
\hline
\end{tabular}




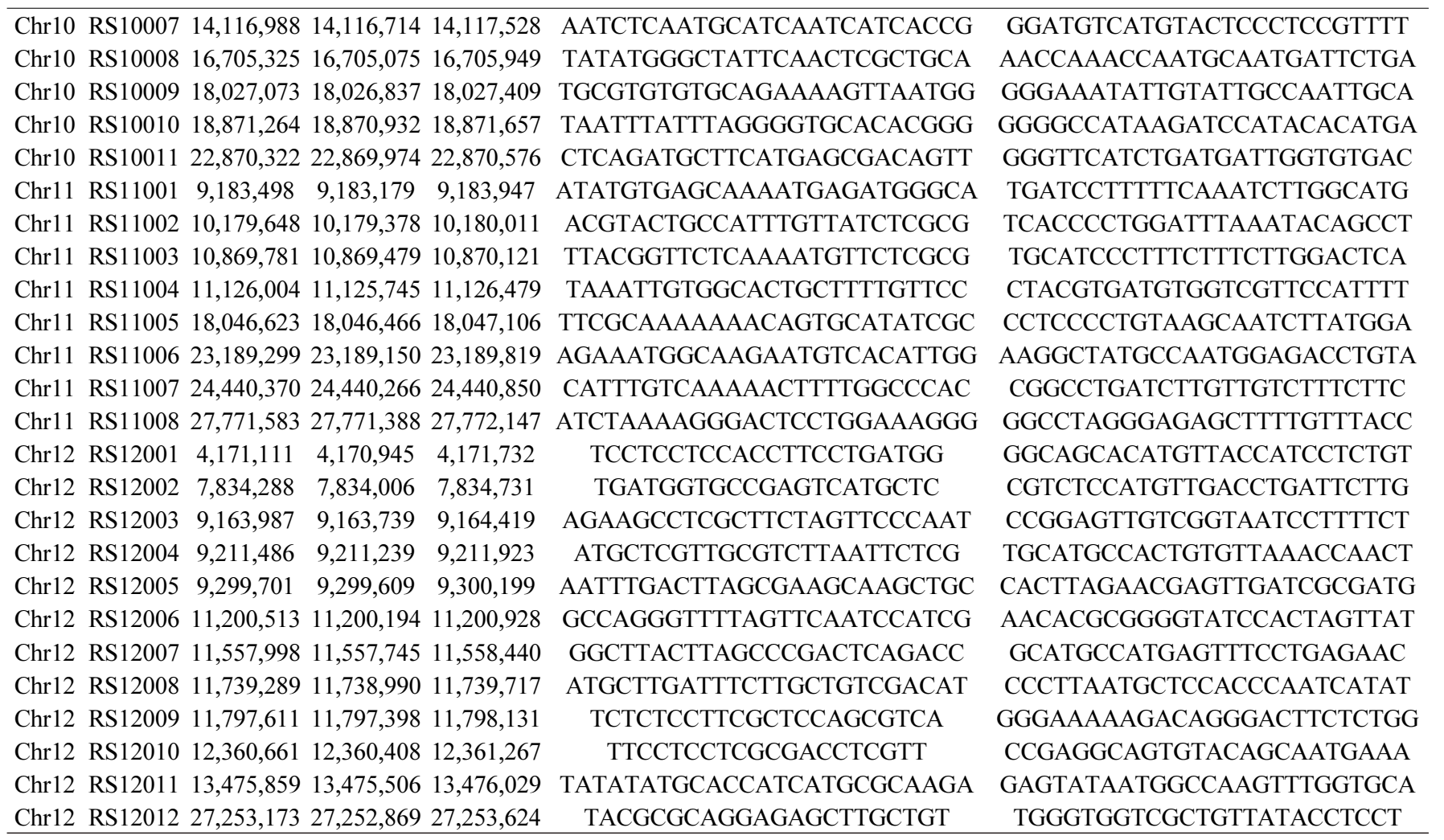

은 그래프 범위 내에 작성된 수치와 두 모본의 평균 값이 이전과 유사하게 나타났다. 줄기 굵기에서는 줄기가 굵을수록 수장의 길이가 길어지는 경향을 나타냈고, 수장과 수수 형질에 대해서도 유의성이 있는 상관관계를 확인할 수 있었다(Table 3). 그러나, 간장 형질에 대해서는 줄기 굵기 형질과 낮은 상관관계를 갖거나 나타나지 않는 것을 확인할 수 있었다. 줄기 굵기, 수장과 수수의 형질에서는 서로 유의성이 있는 상관관계를 확인할 수 있었지만 간장에서는 이들에 대해 낮은 상관관계가 나타난 것을 보았을 때, 줄기 굵기가 굵어지거나 수장의 길이가 길어지더라도 간장에 큰 영향을 미치지 못한다는 것을 추측할 수 있었다.

\section{벼의 7가지 형질 관련 QTL 분석}

MGRIL 집단을 이용하여 통합된 유전지도를 바탕으로 벼의 생산성 향상과 관련이 있는 주요 형질 중 하나인 줄기 굵기에서 총 9개의 QTL이 새로 탐색되었다(Table 4). 1절 줄기 굵기에서 는 총 3개의 QTL이 탐색되었으며, 이를 qI1D-1, qI1D-6, qI1D-10으로 명명하였다. LOD 값은 각각 4.8, 5.1, 3.2로 qI1D-6이 전체 중 가장 높았으며, 표현형 변이는 3 개 모두 밀양 23호의 대립형질(allele)이 1절 줄기를 증가시켰다. 2절 줄기 굵기도 총 3 개의 QTL로 이들을 qI2D-1, qI2D-5, qI2D-7로
명명하였다. 새로 탐색된 QTL 중 qI2D-1는 유일하게 기호벼의 대립형질을 증가시켰으며, 표현형 변이는 각각 $46.56 \%$, $46.84 \%, 51.93 \%$ 이었다. 3절 줄기 굵기에서는 qI3D-7, qI3D-8 로 명명된 2개의 신규 QTL이 나타났으며, LOD 값은 각각 3.3 과 3.5 로 밀양 23 호의 대립형질이 증가하였다. 4절 줄기 굵기 형질에서는 4.0의 LOD값을 가진 qI4D-10로 명명된 1개의 QTL 이 새로 탐색되었으며, 표현형 변이는 $35.94 \%$ 였다. 각 형질 별로 탐색된 모든 QTL들은 유사한 지역에서 탐색되었다. 특히, 1절과 2절, 2절과 3절 줄기 굵기 관련 형질에서는 이전 보고된 QTL들이 동일한 마커에서 탐색되었으며, 유전지도에 표시하였 다(Fig. 5). 본 연구에서 탐색된 총 29개의 QTL 중 9개의 신규 QTL 이외에도 1차 연구결과(Lee et al. 2014)에서 나타난 8개의 QTL들도 포함하고 있었다. 이 중 줄기 굵기 관련 형질에서 탐색된 6개의 QTL들은 이전 연구와 동일한 것임을 확인하였다. 비록, 간장, 수장, 수수의 신규 QTL은 발견되지 않았지만, 전체 7 가지 형질과 연관된 QTL의 수를 보았을 때 1 차에 비해 10 개가 증가하였다. 그 결과, 이전보다 증가된 마커 수와 그로 인해 얻어진 QTL 수가 함께 늘어나면서, 1차보다 2차에서 마커 간 상대적 거리가 줄어들어 QTL 신뢰성이 향상된 유전지도를 얻을 수 있었다. 새로 탐색된 9개의 QTL들은 서로 다른 유전자에 


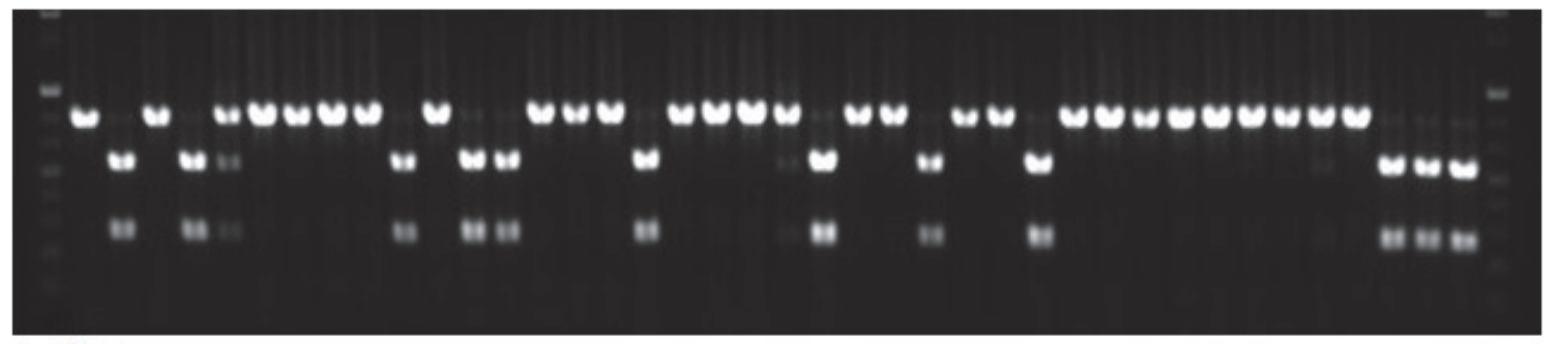

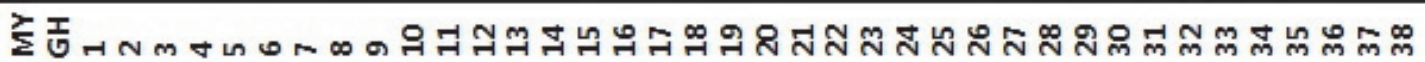

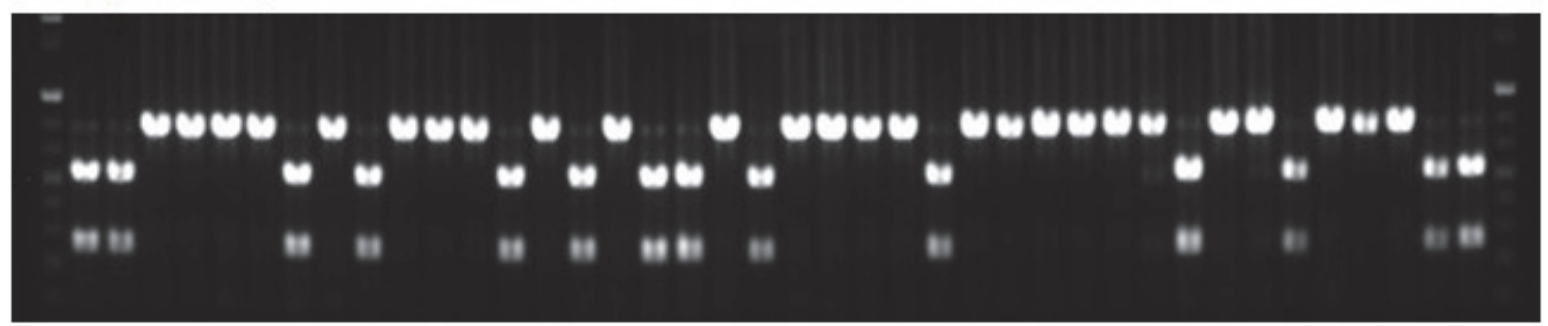

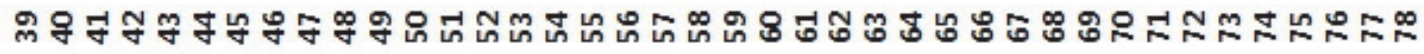

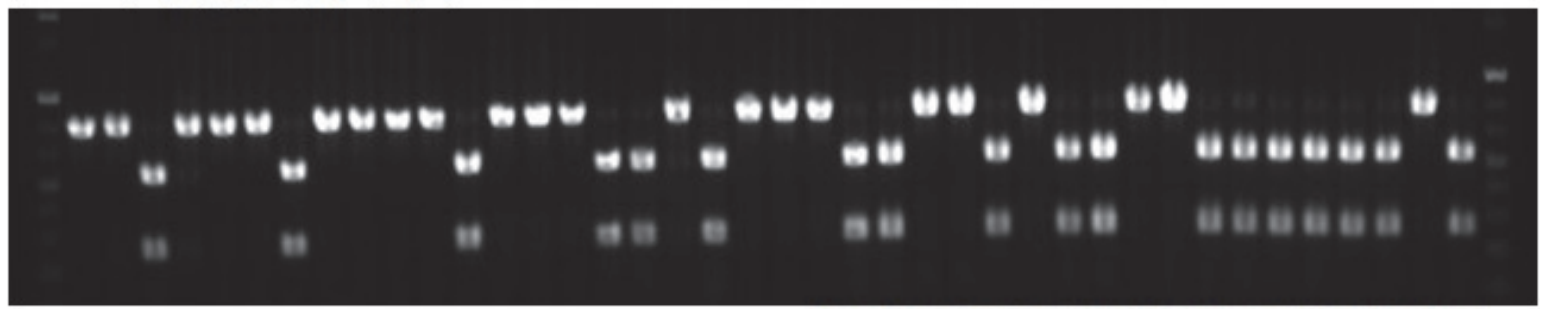

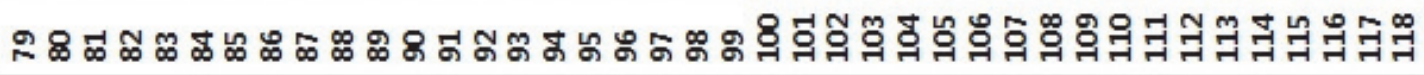

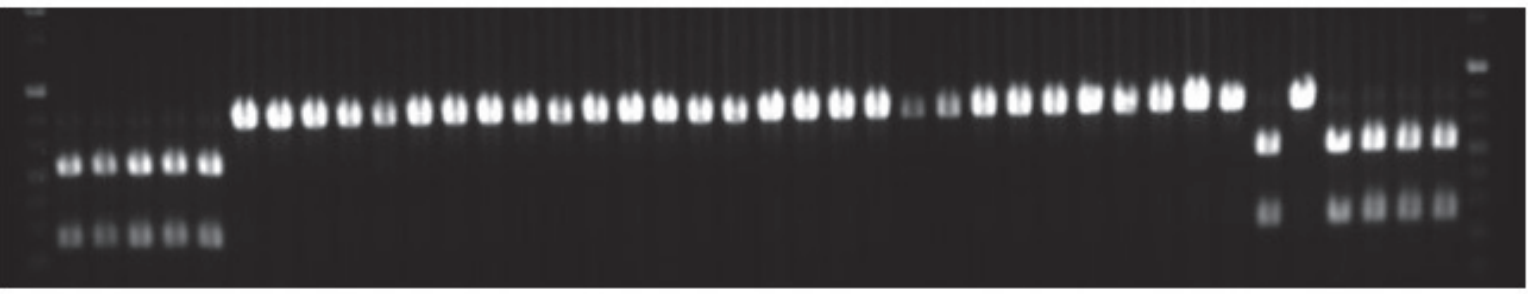

马ి

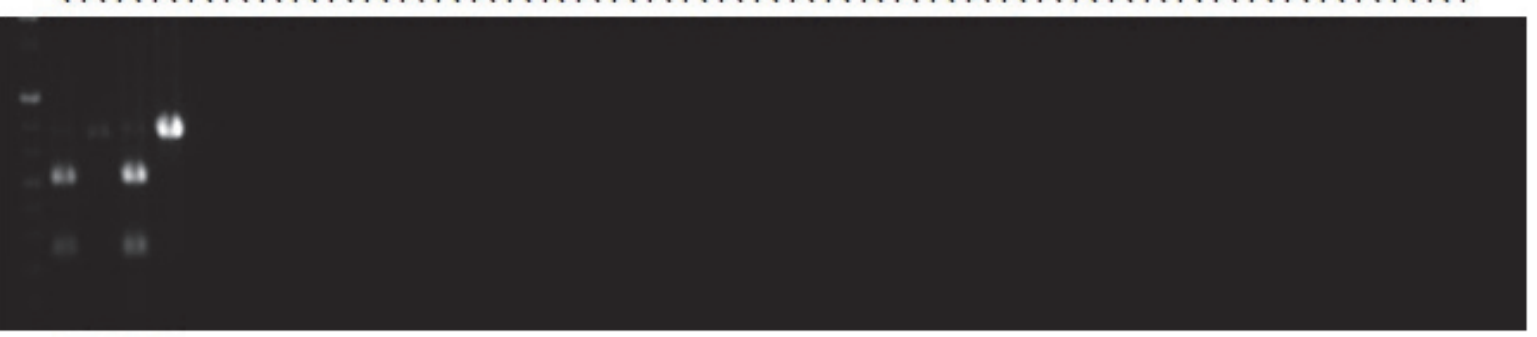

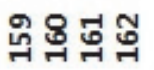

Fig. 1. Example of genotyping in the MGRIL population.

In this experiment, the marker name is RS06005 and PCR product size was 752bp. After restriction enzyme digestion using HindIII, Gihobyeo allele was divided to $240 \mathrm{bp}$ and $512 \mathrm{bp}$ fragments. 'MY' indicates Milyang23 and 'GH' indicates Gihobyeo. Each of left and right ends is size marker. 
Table 3. Correlation coefficients among the seven traits measured in the population of MGRIL.

\begin{tabular}{|c|c|c|c|c|c|c|c|}
\hline Trait $^{Z}$ & I1D & $\mathrm{I} 2 \mathrm{D}$ & $\mathrm{I} 3 \mathrm{D}$ & I4D & $\mathrm{CL}$ & PL & $\mathrm{PN}$ \\
\hline I1D & 1.000 & & & & & & \\
\hline $\mathrm{I} 2 \mathrm{D}$ & $0.831^{* *}$ & 1.000 & & & & & \\
\hline I4D & $0.581^{* *}$ & $0.788^{* *}$ & $0.935^{* *}$ & 1.000 & & & \\
\hline CL & $-0.034\left(\mathrm{~ns}^{\mathrm{y}}\right)$ & $-0.021(\mathrm{~ns})$ & $0.167(\mathrm{~ns})$ & $0.272^{* *}$ & 1.000 & & \\
\hline PN & $-0.413^{* *}$ & $-0.385^{* *}$ & $-0.303 * *$ & $-0.362^{* *}$ & $-0.070(\mathrm{~ns})$ & $-0.256^{* *}$ & 1.000 \\
\hline
\end{tabular}

** Significant at $1 \%$ level of probability $(\mathrm{P}<0.01)$.

${ }^{\mathrm{z}} \mathrm{I} 1 \mathrm{D}$ (first internode diameter), $\mathrm{I} 2 \mathrm{D}$ (second internode diameter), $\mathrm{I} 3 \mathrm{D}$ (third internode diameter), I4D(fourth internode diameter), CL(culm length), PL(panicle length), PN(panicle number)

${ }^{\mathrm{y}}$ ns, not significant

Table 4. Characteristics of QTLs detected for seven traits with MGRILs.

\begin{tabular}{|c|c|c|c|c|c|c|c|c|c|}
\hline Trait & No. & $\begin{array}{l}\text { QTL } \\
\text { name }^{\mathrm{z}}\end{array}$ & Chr\# & $\begin{array}{l}\text { Position } \\
(\mathrm{cM})\end{array}$ & $\begin{array}{l}\text { Peak } \\
\text { LOD }^{y}\end{array}$ & $\mathrm{R}_{2} /(\%)^{\mathrm{x}}$ & $\begin{array}{l}\text { Additive } \\
\text { effect }^{\mathrm{w}}\end{array}$ & $\begin{array}{l}\text { Flanking } \\
\text { markers }\end{array}$ & Reference \\
\hline \multirow{5}{*}{$\begin{array}{c}\text { First } \\
\text { internode } \\
\text { (I1D) }\end{array}$} & 1 & qI1D-1 & 1 & 16.3 & 4.8 & 10.89 & 0.11 & $\begin{array}{l}\text { RM1247, } \\
\text { RS012 }\end{array}$ & \\
\hline & 2 & & 1 & 36.1 & 11.0 & 22.74 & 0.15 & $\begin{array}{l}\text { RS01001 } \\
\text { STS01007 }\end{array}$ & Kashiwagi \& Ishimaru (2004) \\
\hline & 3 & & 5 & 80.9 & 4.7 & 8.20 & 0.09 & $\begin{array}{l}\text { RS0577, } \\
\text { RM6841 }\end{array}$ & qI1D5 (Lee et al. 2014) \\
\hline & 4 & qI1D-6 & 6 & 106.7 & 5.1 & 10.28 & 0.10 & $\begin{array}{l}\text { RS0691, } \\
\text { RM1370 }\end{array}$ & \\
\hline & 5 & qI1D-10 & 10 & 16.1 & 3.2 & 5.12 & 0.07 & $\begin{array}{l}\text { STS10014, } \\
\text { RS10003 }^{v}\end{array}$ & \\
\hline \multirow{6}{*}{$\begin{array}{l}\text { Second } \\
\text { internode } \\
\text { (I2D) }\end{array}$} & 6 & & 1 & 28.1 & 8.9 & 15.36 & 0.18 & $\begin{array}{c}\text { RM1, } \\
\text { RS01001 }^{\mathrm{v}}\end{array}$ & $\begin{array}{l}\text { sdm1 (Kashiwagi et al. 2008) } \\
\text { Lee et al. } 2014\end{array}$ \\
\hline & 7 & qI2D-1 & 1 & 205.8 & 3.3 & 5.39 & -0.11 & $\begin{array}{l}\text { STS01039, } \\
\text { RS0124 }\end{array}$ & \\
\hline & 8 & qI2D-5 & 5 & 79.9 & 4.8 & 7.79 & 0.13 & $\begin{array}{l}\text { RS0577, } \\
\text { RM6841 }\end{array}$ & \\
\hline & 9 & & 6 & 108.7 & 5.9 & 12.02 & 0.17 & $\begin{array}{l}\text { RS0691, } \\
\text { RM1370 }\end{array}$ & $\begin{array}{l}\text { Kashiwagi \& Ishimaru (2004) } \\
\text { Lee et al. } 2014\end{array}$ \\
\hline & 10 & qI2D-7 & 7 & 64.3 & 3.4 & 4.96 & 0.11 & $\begin{array}{l}\text { STS07023, } \\
\text { RS07100 }\end{array}$ & \\
\hline & 11 & & 10 & 57.6 & 5.6 & 9.21 & 0.15 & $\begin{array}{c}\mathrm{RS} 10010^{\mathrm{v}} \\
\mathrm{RS} 10124\end{array}$ & Ishimaru et al. 2001 \\
\hline \multirow{3}{*}{$\begin{array}{c}\text { Third } \\
\text { internode } \\
\text { (I3D) }\end{array}$} & 12 & & 1 & 205.8 & 3.4 & 6.33 & -0.16 & $\begin{array}{l}\text { RS0124, } \\
\text { RS0125 }\end{array}$ & qI3D1 (Lee et al. 2014) \\
\hline & 13 & & 4 & 87.5 & 3.2 & 6.06 & -0.16 & $\begin{array}{l}\text { RS0463, } \\
\mathrm{RS}^{2} 4007^{\mathrm{v}}\end{array}$ & $\begin{array}{l}\text { Lee et al. } 2014 \\
\text { qCD-4 (Wang et al. 2011) }\end{array}$ \\
\hline & 14 & & 6 & 106.7 & 5.9 & 14.49 & 0.24 & $\begin{array}{l}\text { RS0691, } \\
\text { RM1370 }\end{array}$ & $\begin{array}{l}\text { Kashiwagi \& Ishimaru (2004) } \\
\text { Lee et al. } 2014\end{array}$ \\
\hline
\end{tabular}




\begin{tabular}{|c|c|c|c|c|c|c|c|c|c|}
\hline & 15 & qI3D-7 & 7 & 14.5 & 3.3 & 1.73 & 0.16 & $\begin{array}{l}\text { RM5055, } \\
\text { RS07001 }\end{array}$ & \\
\hline & 16 & qI3D-8 & 8 & 31.5 & 3.5 & 14.18 & 0.24 & $\begin{array}{l}\text { STS08008, } \\
\text { RM22608 }\end{array}$ & \\
\hline & 17 & & 10 & 59.6 & 5.4 & 10.71 & 0.21 & $\begin{array}{l}\text { RS10010v, } \\
\text { RS10124 }\end{array}$ & Ishimaru et al. 2001 \\
\hline \multirow{4}{*}{$\begin{array}{l}\text { Fourth } \\
\text { internode } \\
\text { (I4D) }\end{array}$} & 18 & & 1 & 52.3 & 3.7 & 7.20 & 0.19 & $\begin{array}{l}\text { RTM4211, } \\
\text { RS015 }\end{array}$ & Kashiwagi \& Ishimaru (2004) \\
\hline & 19 & & 1 & 204.4 & 3.0 & 6.50 & -0.18 & $\begin{array}{l}\text { STS01039, } \\
\text { RS0124 }\end{array}$ & qI4D1 (Lee et al. 2014) \\
\hline & 20 & & 6 & 88.0 & 7.2 & 15.57 & 0.30 & $\begin{array}{l}\text { RS06005 } \\
\text { RS0690 }\end{array}$ & Kashiwagi \& Ishimaru (2004) \\
\hline & 21 & qI4D-10 & 10 & 24.9 & 4.0 & 7.81 & 0.21 & $\begin{array}{c}\text { STS10017, } \\
\text { RS10121 }\end{array}$ & \\
\hline \multirow{3}{*}{$\begin{array}{l}\text { Culm } \\
\text { length } \\
\text { (CL) }\end{array}$} & 22 & & 1 & 181.8 & 40.2 & 65.14 & -11.68 & $\begin{array}{l}\text { RS0119, } \\
\text { RS0120 }\end{array}$ & $\begin{array}{l}\text { sd-1 (Ashikari et al. 2002, } \\
\text { Cho et al. 1994, } \\
\text { Lee et al. 2014 } \\
\text { Monna et al. 2002, } \\
\text { Sasaki et al. 2002, } \\
\text { Spielmeyer et al. 2002) }\end{array}$ \\
\hline & 23 & & 5 & 1.3 & 3.4 & 1.95 & 2.55 & $\begin{array}{l}\text { RM17960, } \\
\text { RM17962 }\end{array}$ & cl5b (Mu et al. 2004) \\
\hline & 24 & & 6 & 96.1 & 6.6 & 6.42 & 3.83 & $\begin{array}{l}\text { RS06006 } \\
\text { RS06007 }\end{array}$ & qCL-6 (Yamamoto et al. 2001) \\
\hline \multirow{3}{*}{$\begin{array}{l}\text { Panicle } \\
\text { length } \\
\text { (PL) }\end{array}$} & 25 & & 3 & 29.6 & 5.0 & 9.21 & 0.74 & $\begin{array}{l}\text { RS03004 } \\
\text { RS03005 }\end{array}$ & $\begin{array}{l}\text { qPL-3-1 (Yamamoto et al. 2001) } \\
\text { pl3b (Zhuang et al. 1997) }\end{array}$ \\
\hline & 26 & & 3 & 140.0 & 3.1 & 2.56 & -0.56 & $\begin{array}{l}\text { RS0355, } \\
\text { RS0356 }\end{array}$ & qPL-3-2 (Yamamoto et al. 2001) \\
\hline & 27 & & 5 & 48.2 & 4.4 & 8.00 & 0.65 & $\begin{array}{l}\text { R5M20, } \\
{\text { RS} 05003^{v}}^{\text {v }}\end{array}$ & $\begin{array}{l}\text { pl5.1 (Marri et al. 2005) } \\
\text { Xiao et al. } 1996 \\
\text { Yoshida et al. } 2002\end{array}$ \\
\hline \multirow{2}{*}{$\begin{array}{l}\text { Panicle } \\
\text { number } \\
(\mathrm{PN})\end{array}$} & 28 & & 1 & 37.1 & 3.9 & 11.07 & -0.53 & $\begin{array}{l}\text { RS01001 } \\
\text { STS01007 }\end{array}$ & $\begin{array}{l}\text { Cho et al. } 2003 \\
\text { Jiang et al. } 2004 \\
\text { Kobayashi et al. } 2003 \\
\text { Nagata et al. } 2002\end{array}$ \\
\hline & 29 & & 5 & 41.7 & 3.5 & 7.56 & -0.44 & $\begin{array}{l}\text { R5M13, } \\
\text { RS0573 }\end{array}$ & $\begin{array}{l}\text { Kobayashi et al. } 2003 \\
\text { Lin et al. } 1996\end{array}$ \\
\hline
\end{tabular}

${ }^{\mathrm{z}}$ Newly QTLs which named q+trait, -chromosome number.

${ }^{\mathrm{y}}$ The logarithm of the ratio of two likelihoods.

${ }^{\mathrm{x}}$ The percentage of evaluated phenotype variation explained by each QTL.

${ }^{\text {w}}$ Position and negative values indicated additive effect contributed by the alleles of Milyang23 and Gihobyeo.

${ }^{\mathrm{v}} 101$ CAPS markers newly developed in this study.

의해 지배될 확률도 있으므로 각각 이름을 다르게 하여 임의로 명명하였다. 그러나, 기존 보고된 연구들과의 교배나 측정방법의 기준 등이 다르기 때문에 이에 대한 연구는 더 필요하다(Lee et al. 2014, Lin et al. 1996, Wu et al. 1996, Xiao et al. 1998, Zhuang et al. 1997). 이러한 QTL 분석 결과들은 실질적인
육종을 수행하는데 기반이 될 것이며, 농업적으로 유익한 정보로 이용될 것이다. 
Chr1

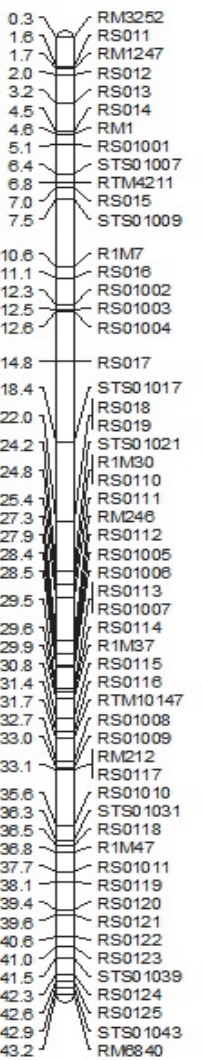

Chr7
Chr2

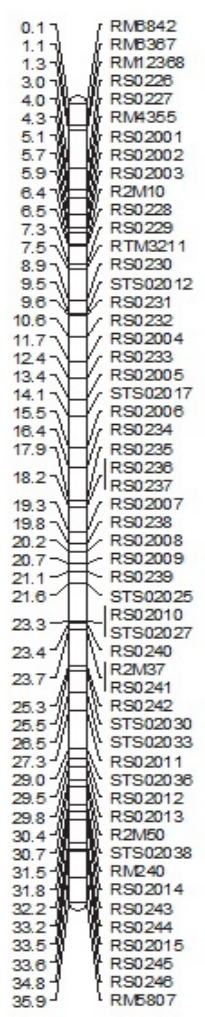

Chr8

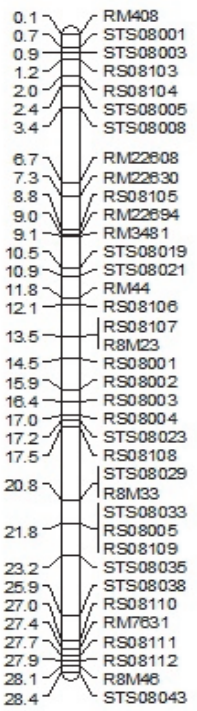

Chr3

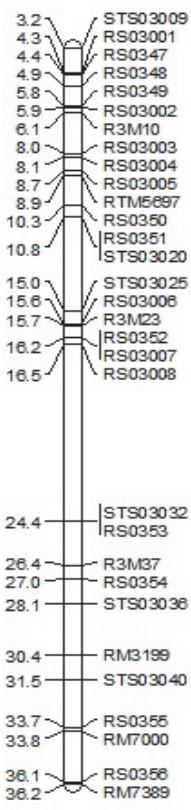

Chr9

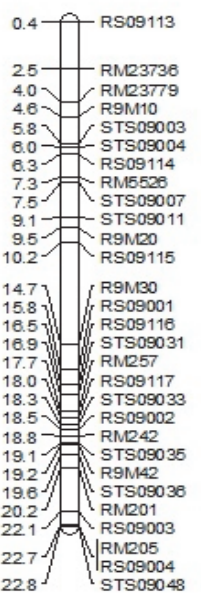

Chr4

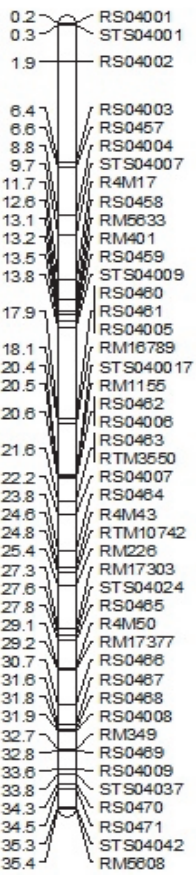

Chr10

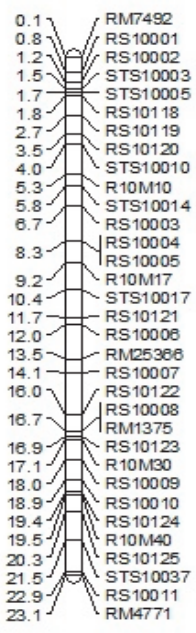

Chr5

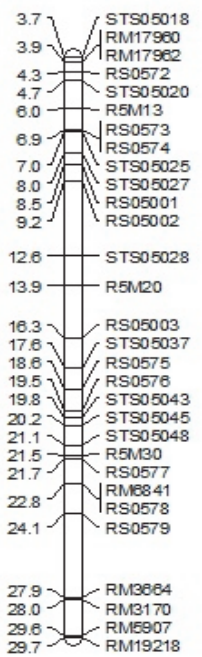

Chr11

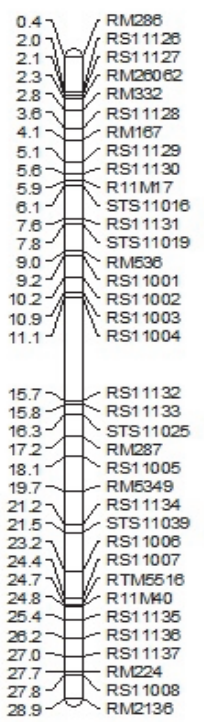

Chr6

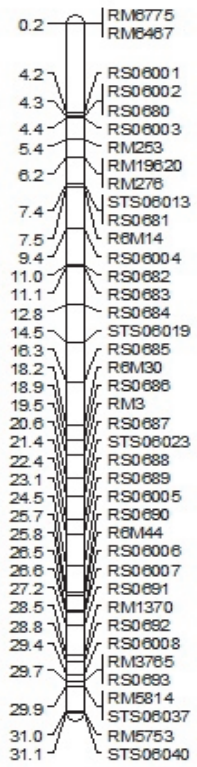

Chr12

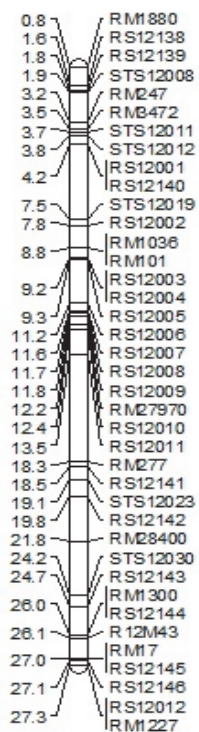

Fig. 2. The physical map constructed using MGRIL population.

Chromosome numbers are indicated on top of chromosome, the name of each marker is at the right side of chromosome, and the physical distance of each marker from the first marker at the top of each chromosome is at the left side. Physical distance, measured as mega base pair(Mbp). 
Chr1

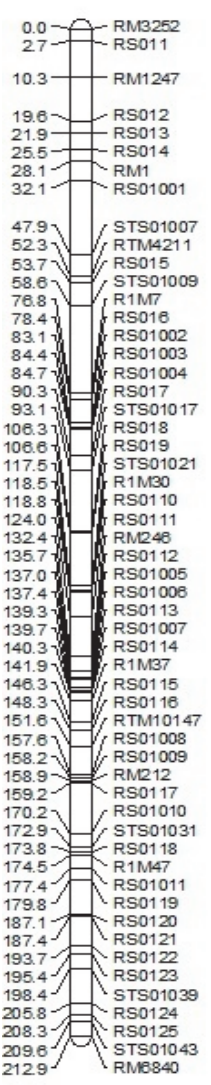

Chr7

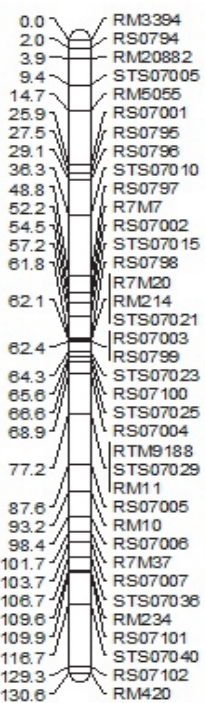

Chr2
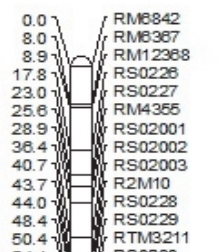

54.1 .

68.1 - RSO231

70.5 . 74 RSO232

75.9 谓- RS02005

$78.2 \mathrm{TSTS2017}$

81.8 O RS0234

83.4 $=$ RSO235

$89.3-$ - RSO2007

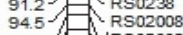

96.8 M RS02009

108.9.

09.1 - STSO202

109.5 H R R024

110.4 - RSO241

119.3.

128.9
137.4
STSO2030

139.3

140.9
1425
$\mathrm{R} 2 \mathrm{M} 02013$

45.4 - STSO2033

48.8 RM240

150.4 f RS0243

154.6 RS02015

184.4 RSO246

Chr8

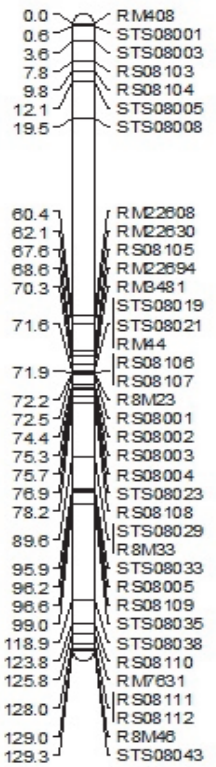

Chr3

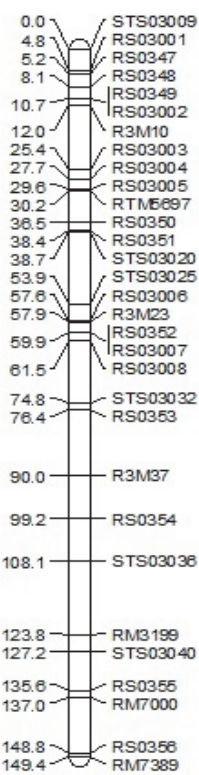

Chr9

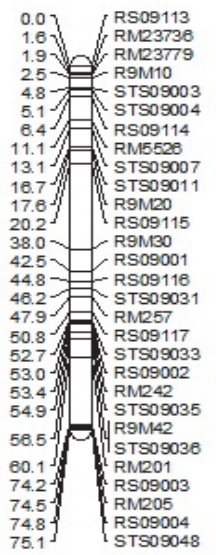

Chr4

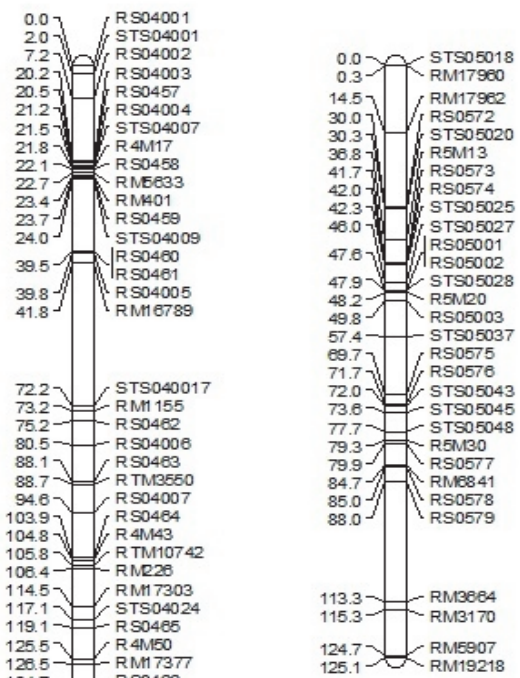

Chr10

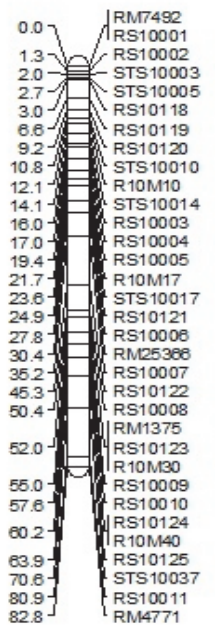

Chr11

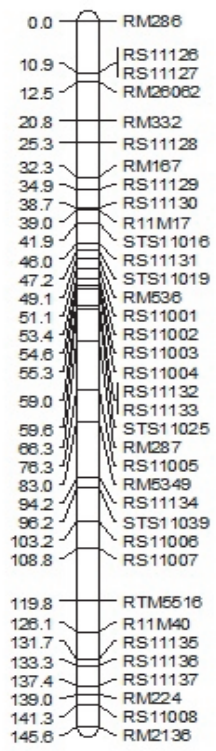

Chr6

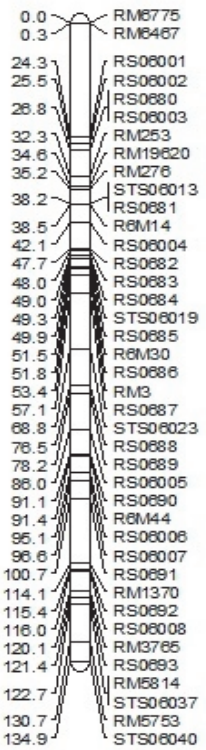

Chr12

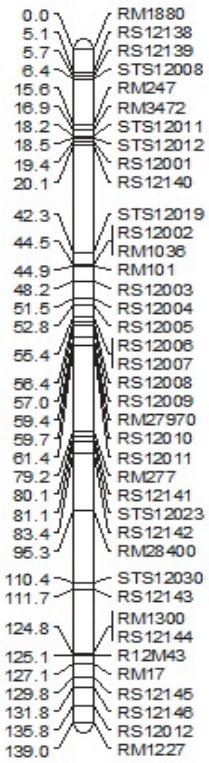

Fig. 3. The genetic map constructed using MGRIL population.

Chromosome numbers are indicated on top of chromosome, the name of each marker is at the right side of chromosome, and the genetic distance of each marker from the first marker at the top of each chromosome is at the left side. Genetic distance, measured as centimorgan or $\mathrm{cM}$, is calculated using Kosambi function. 

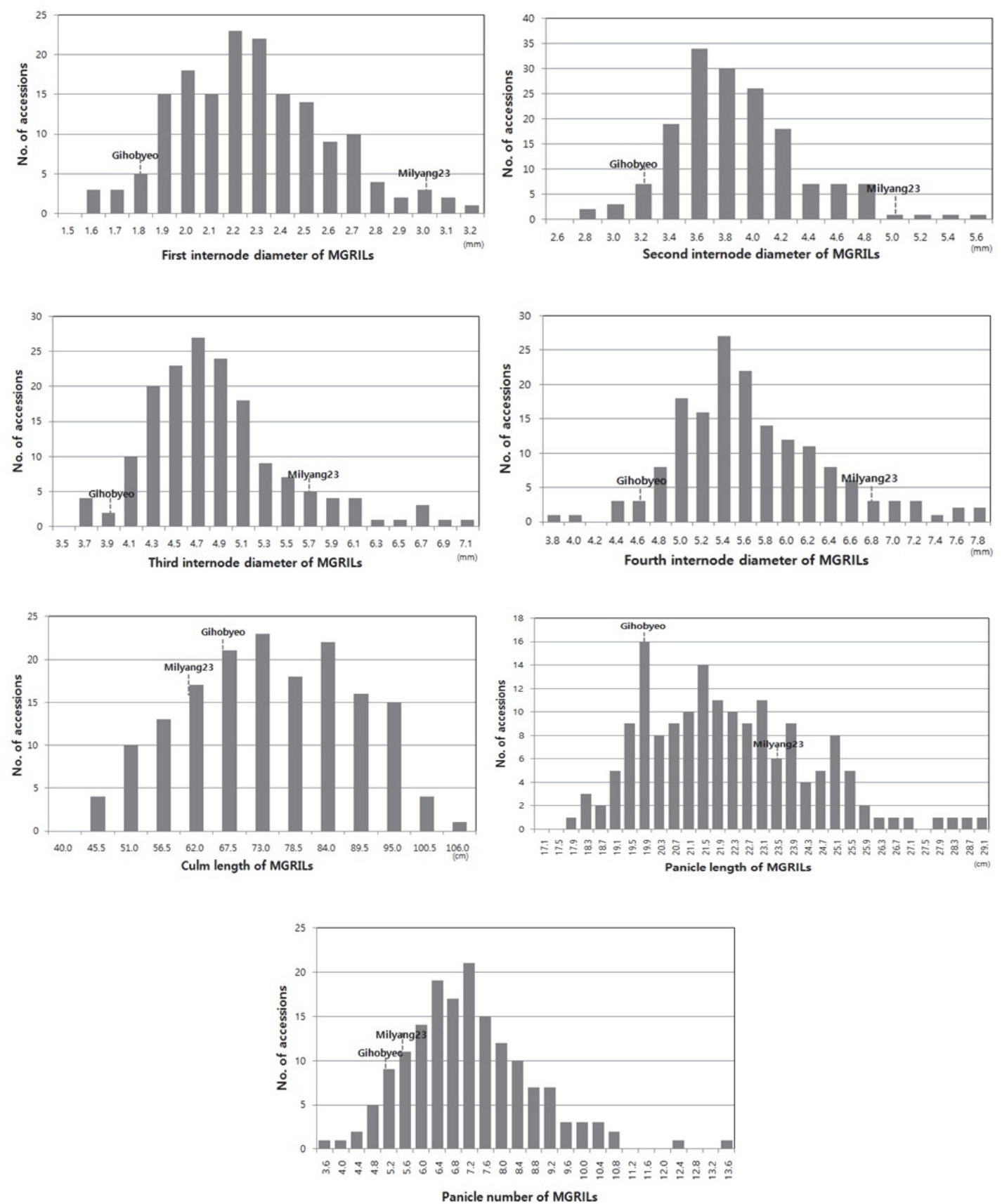

Fig. 4. Frequency distribution in histograms showing seven traits measured in MGRIL population. Mean of the parents are indicated at the top of each histogram, with lines representing Gihobyeo and Milyang23 respectively.

\section{적 요}

차세대 염기서열 분석방법을 통해 밀양 23 호와 기호벼의 유전 체 서열을 분석하여 변이를 탐색하였다. 대량으로 생산된 $\mathrm{SNP}$ 을
기반으로 Lee et al. (2014)이 선발한 후보 CAPS 마커 중에서 4개의 제한효소(EcoR I, HindIII, Pst I, Xho I ) 자리에 위치한 특이적인 SNP을 후보 CAPS 마커로 개발하였다. 후보 CAPS 마커 7,843 개 중 101 개가 안정적인 CAPS 마커로 개발되었다. 

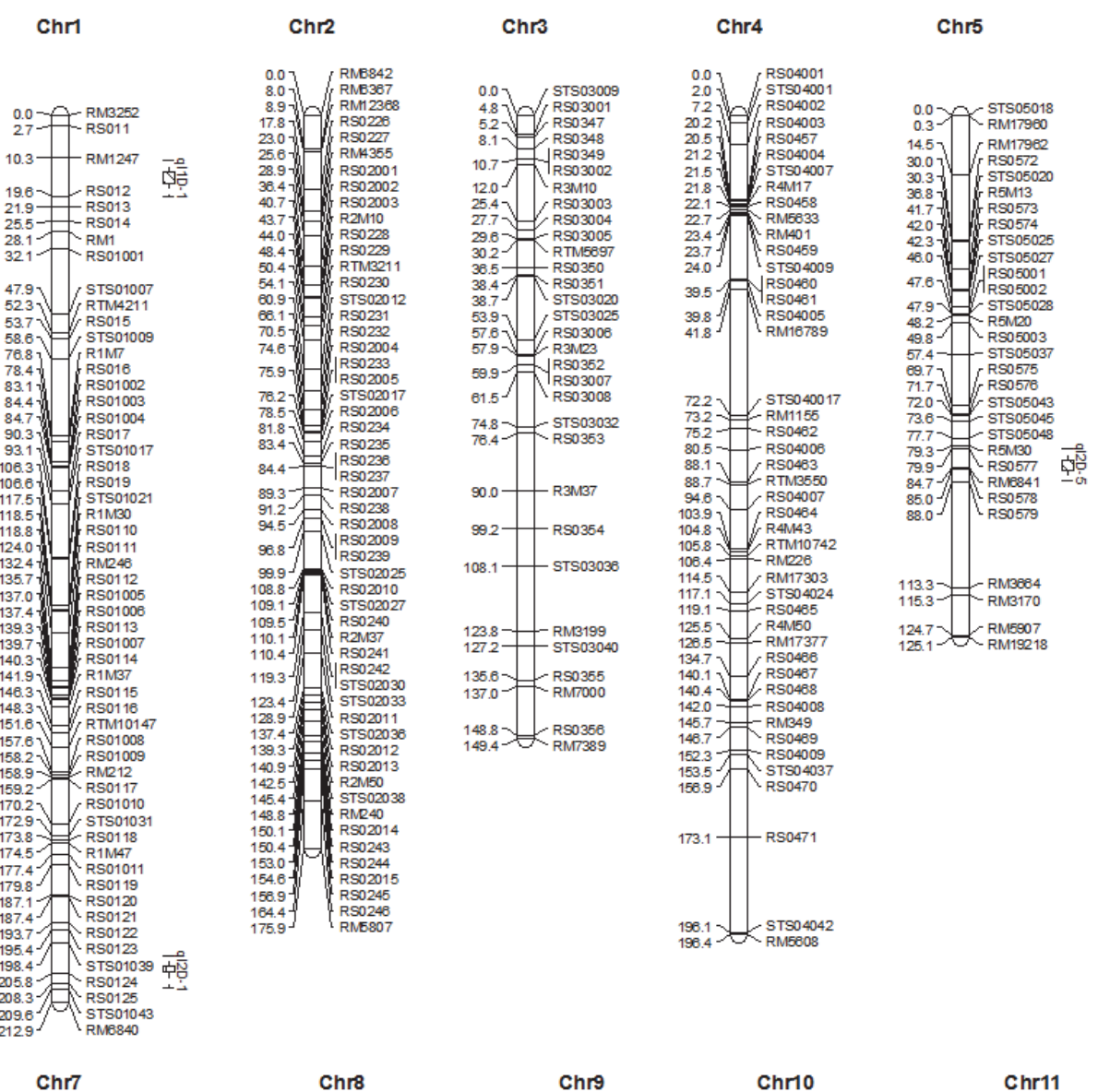

Chr6
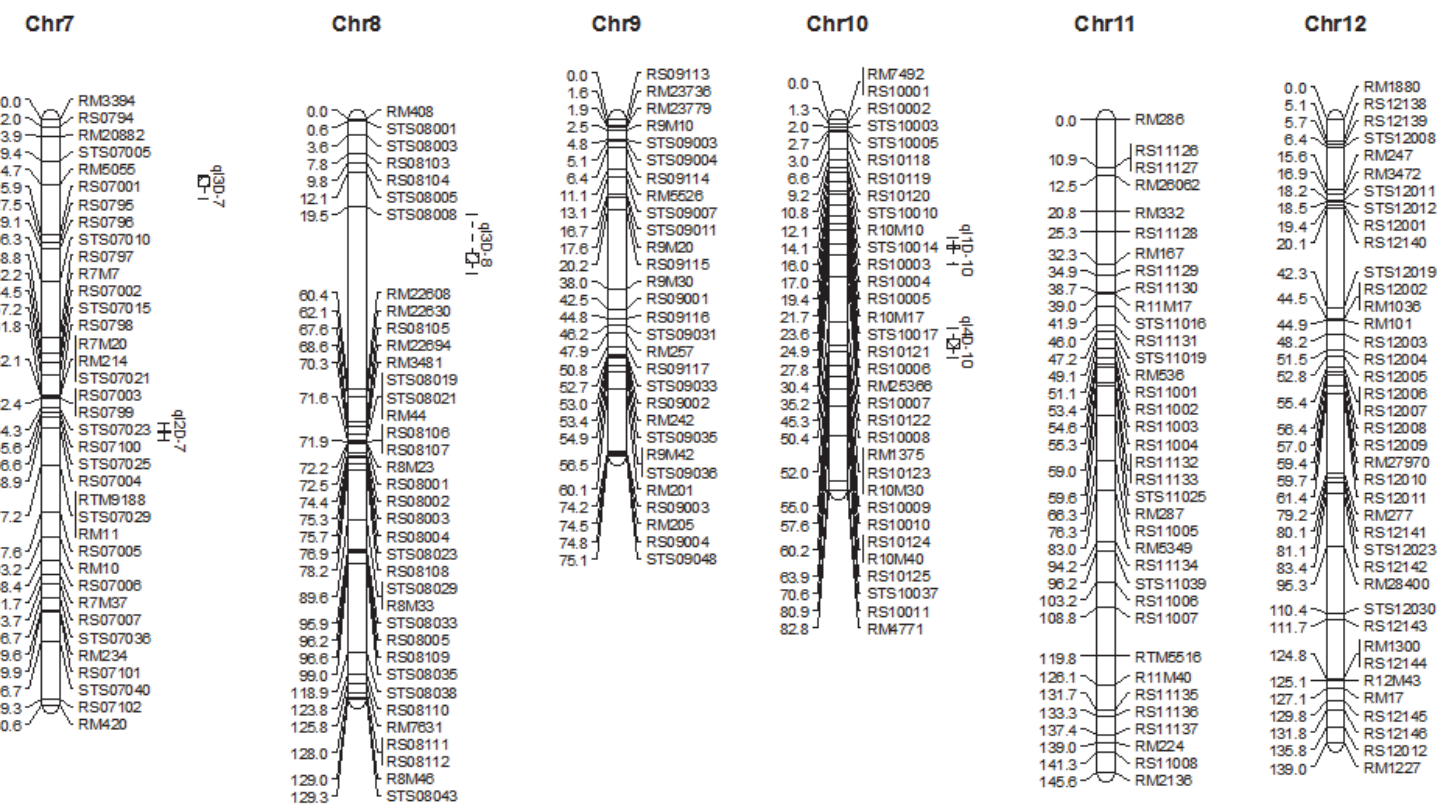

Fig. 5. Position of QTLs for seven traits measured in this study with MGRIL population.

The locations of QTLs for the first internode diameter(I1D), the second internode diameter(I2D), the third internode diameter(I3D) and the fourth internode diameter(I4D) were shown on the genetic map. 
이들 CAPS 마커를 PCR 기반 마커들로 구성된 Lee et al. (2014) 연구의 유전지도와 통합하여 보다 정밀해진 분자유전지도를 작성하였다. 총 유전거리는 $1,696.97 \mathrm{cM}$ 였으며, 마커 간 평균거 리는 $3.64 \mathrm{cM}$ 로 이전 연구에 비해 거리가 줄어든 것을 확인하였 다. 또한, 벼의 줄기 굵기 형질에 대해 QTL을 탐색한 결과, 총 9개의 유의성이 있는 QTL을 찾을 수 있었으며 모두 기존에 보고되지 않은 새로운 QTL이었다. 간장, 수장 그리고 수수 형질 에 관한 새로운 QTL은 발견되지 않았지만, 7가지 형질에 대한 주동 및 미동 QTL 중 일부는 본 연구에서 새롭게 개발한 CAPS 마커로 확인되었으며 보다 정밀한 QTL 유전지도 작성이 가능하 였다. NGS 기반 CAPS 마커로 작성된 분자유전지도를 통해 높은 정확성과 신규로 개발된 QTL의 신뢰성을 확인하였으며, 이를 이용하여 향후 대량의 마커를 이용하여 고밀도 유전지도를 작성하고 이에 대한 QTL 분석을 통해 농업적으로 유용하게 쓰일 수 있을 것이다.

\section{사 사}

본 연구는 농촌진흥청 어젠다 1-5-15(과제번호:PJ010089) “벼 고밀도 유전지도 기반 생산성 관련 분자마커 개발" 과제 지원에 의해 수행되었다.

\section{REFERENCES}

1. Asano K, Takashi T, Miura K, Qian Q, Kitano H, Matsuoka M, Ashikari M. 2007. Genetic and molecular analysis of utility of sd1 alleles in rice breeding. Korean J. Breed Sci. 57: 53-58.

2. Ashikari M, Sasaki A, Ueguchi-Tanaka M, Itoh H, Nishimura A, Datta S, Ishiyama K, Saito T, Kobayashi M, Khush GS. 2002. Loss-of-function of a rice gilbberellin biosynthetic gene, GA20 oxidase (GA20ox-2), led to the rice 'green revolution'. Korean J. Breed Sci. 52: 143-150.

3. Cho YC, Suh JP, Choi IS, Hong HC, Baek MK, Kang KH, Kim YG, Ahn SN, Choi HC, Hwang HG, Moon HP. 2003. QTLs analysis of yield and its related traits in wild rice relative Oryza rufipogon. Treat Crop Res. 4: 19-29.

4. Cho YG, Eun MY, McCouch SR, Chae YA. 1994. The semidwarf gene, $s d-1$, of rice (Oryza sativa L.). II. Molecular mapping and marker-assisted selection. Theor.
Appl. Genet. 89: 54-59.

5. Cho YG, Kang MR, Kim YW, Eun MY, Chung TY, Lee YT. 1998a. Development of RFLP Framework map of Rice (Oryza sativa L.) using recombinant inbred population derived from Milyang23/Gihobyeo cross. Korean J. Breed Sci. 30: 289-297.

6. Cho YG, McCouch SR, Kuiper M, Kang MR, Pot J, Groenen J, Eun MY. 1998b. Intergrated map of AFLP, SSLP and RFLP markers using a recombinant inbred population of rice (Oryza sativa L.). Theor. Appl. Genet. 97: 370-380.

7. Harushima Y, Yano M, Shomura A, Sato M, Shimano T, Kuboki Y, Yamanoto T, Lin SY, Antonio BA, Parco A, Kajiya H, Huang N, Yamamoto K, Nagamura Y, Kurata N, Khush GS, Sasaki T. 1998. A high-density rice genetic linkage map with 2275 markers using a single F2 population. Genetics 148: 479-494.

8. Huq MA, Akter S, Jung YH, Nou IS, Cho YG, Kang KK. 2016. Genome sequencing, a milestone for genomic research and plant breeding. Plant Breed. Biotech. 4: 29-39.

9. Ishimaru K, Yano M, Aoki N, Ono K, Hirose T, Lin SY, Monna L, Sasaki T, Ohsugi R. 2001. Toward the mapping of physiological and agronomic characters on a rice function map: QTL analysis and comparison between QTLs and expressed sequence tags. Theor. Appl. Genet. 102: 793-800.

10. Jeong IS, Yoon UH, Lee GS, Ji HS, Lee HJ, Han CD, Hahn JH, Kim TH. 2013. SNP-based analysis of genetic diversity in anther-derived rice by whole genome sequencing. Rice 6: 1-12.

11. Ji H, Kim H, Lee GS, Yoon UH, Kim TH, Seol YJ, Yun DW, Koh HJ, Eun MY. 2012. Development of rice molecular genetic and physical map using PCR-based DNA markers with the recombinant inbred population derived from Milyang23/Gihobyeo cross. Korean J. Breed Sci. 44: 273-281.

12. Jiang GH, Xu CG, Li XH, He YQ. 2004. Characterization of the genetic basis for yield and its component traits of rice revealed by doubled haploid population. Acta genetica Sinica 31: 63-72.

13. Kang HJ, Cho YG, Lee YT, Eun MY, Shim JU. 1998. QTL mapping of genes conferring days to heading, culm length and panicle length based on molecular map of rice (Oryza sativa L.). RDA J. Crop Sci. 40: 55-61. 
14. Kang HJ, Cho YG, Lee SY, Lee YT, Eun MY, Shim JU. 1999a. Identification of QTL associated with yield and its components based on molecular map in rice. Korean J. Breed Sci.31: 40-47.

15. Kang HJ, Cho YG, Lee YT, Kim HS, Eun MY, Shim JU. 1999b. Detection of putative QTL conferring grain size and shape in rice. Korean J. Breed Sci. 31: 330-335.

16. Kashiwagi T, Ishimaru L. 2004. Identification and functional analysis of a locus for improvement of lodging resistance in rice. Plant Physiol. 134: 676-683.

17. Kashiwagi T, Togawa E, Hirotsu N. 2008. Improvement of lodging resistance with QTLs for stem diameter in rice (Oryza sativa L.). Theor. Appl. Genet. 117: 749-757.

18. Kobayashi S, Fukuta Y, Sato T, Osaki M, Khush GS. 2003. Molecular marker dissection of rice (Oryza sativa L.) plant architecture under temperate and tropical climates. Theor. Appl. Genet. 107: 1350-1356.

19. Kwak TS, Yeo JH, Eun MY, Cha YS. 2004. QTL for quality properties in the Milyang23xGihobyeo recombinant inbred lines by different locations. Korean J. Crop Sci. 49: 539-545.

20. Kwak TS, Yeo JH, Eun MY. 2005. Varietal variation of ripened grain and yield related character in the recombinant inbred lines of the Milyang23xGihobyeo based on the days from seeding to heading. Korean J. Intl. Agri. 17: 112-117.

21. Lee HJ, Jeong IS, Ji H, Lee GS, Yoon UH, Kim TH. 2014. Development of new CAPS markers and their application in QTL analysis of stem diameter in rice. Korean J. Breed Sci. 46: 116-128.

22. Lin HX, Qian HR, Zhuang JY, Lu J, Min SK, Xiong ZM, Huang N, Zheng KL. 1996. RFLP mapping of QTLs for yield and related characters in rice (Oryza sativa L.). Theor. Appl. Genet. 92: 920-927.

23. Lorieux M. 2012. MapDisto:fast and efficient computation of genetic linkage maps. Mol. Breed. 30: 1231-1235.

24. Marri PR, Sarla N, Reddy LV, Siddiq EA. 2005. Identification and mapping of yield and yield related QTLs from an indian accession of Oryza rufipogon. BMC Genetics 6: 1-14.

25. McCouch SR, Kochert G, Yu ZH, Wang ZY, Khush GS, Coffman WR, Tanksley SD. 1988. Molecular mapping of rice chromosomes. Theor. Appl. Genet. 76: 815-829.

26. McCouch SR, Teytelman L, Xu Y, Lobos KB, Clare K, Walton M, Fu B, Maghirang R, Li Z, Xing Y, Zhang Q, Kono I, Yano M, Fjellstrom R, DeClerck G, Schneider D,
Cartinhour S, Ware D, Stein L. 2002. Development and mapping of 2240 new SSR markers for rice (Oryza sativa L.). DNA Res. 9: 199-207.

27. Monna L, Lin H, Kojima S, Sasaki T, Yano M. 2002. Genetic dissection of a genomic region for a quantitative trait locus, $\mathrm{Hd} 3$, into two loci, $\mathrm{Hd} 3 \mathrm{a}$ and $\mathrm{Hd} 3 \mathrm{~b}$, controlling heading date in rice. Theor. Appl. Genet. 104: $772-778$.

28. Mu P, Li ZC, Li CP, Zhang HL, Wang XK. 2004. QTL analysis for lodging resistance in rice using a $\mathrm{DH}$ population under lowland and upland ecosystems. Acta genetica Sinica 31: 717-723.

29. Nagata K, Fukuta Y, Shimizu H, Yagi T, Terao T. 2002. Quantitative trait loci for sink size and ripening traits in rice (Oryza sativa L.). Breed. Sci. 52: 259-273.

30. Nasu S, Suzuki J, Ohta R, Hasegawa K, Yui R, Kitazawa N, Monna L, Minobe Y. 2002. Search for and anlaysis of single nucleotide polymorphisms (SNPs) in rice (Oryza sativa, Oryza Rufipogon) and establishment of SNP markers. DNA Res. 9: 163-171.

31. Ookawa T, Hobo T, Yano M, Murata K, Ando T, Miura H, Asano K, Ochiai Y, Ikeda M, Nishitani R. 2010. New approach for rice improvement using a pleiotropic QTL gene for lodging resistance and yield. Nat. Commun. 1: 132.

32. Sasaki A, Ashikari M, Ueguchi-Tanaka M, Itoh H, Nishimura A, Swapan D, Ishiyama K, Saito T, Kobayashi M, Khush G. 2002. Green revolution: a mutant gibberellins-synthesis gene in rice. Nature 416: 701-702.

33. Spielmeyer W, Ellis M.H, Chandler P.M. 2002. Semidwarf $(s d-1)$, "green revolution" rice, contains a defective gibberellins 20-oxidase gene. Proc. Natl. Acad. Sci. USA 99: 9043-9048.

34. Voorrips RE. 2002. MapChart: software for the graphical presentation of linkage maps and QTLs. J. Hered. 93: 77-78.

35. Wang L, Wang A, Huang X, Zhao Q, Dong G, Qian Q, Sang T, Han B. 2011. Mapping 49 quantitative trait loci at high resolution through sequencing-based genotyping of rice recombinant inbred lines. Theor. Appl. Genet. 122: 327-340.

36. Wang S, Basten C, Zeng Z. 2007. Windows QTL cartogra pher 2.5. Department of Statistics, North Carolina State U niversity, Raleigh, NC. (http://statgen.ncsu.edu/qtlcart/WQ 
TLCart.htm).

37. Wu P, Zhang G \& Huang N. 1996. Identification of QTLs controlling quantitative characters in rice using RFLP markers. Euphytica 89: 349-354.

38. Xiao J, Li J, Yuan L, Tanksley S.D. 1996. Identification of QTLs affecting traits of agronomic importance in a recombinant inbred population derived from a subspecific rice cross. Theor. Appl. Genet. 92: 230-244.

39. Xiao J, Li J, Grandillo S, Ahn S.N, Yuan L, Tanksley S.D, McCouch S.R. 1998. Identification of trait-improving quantitative trait loci alleles from a wild rice relative, Oryza rufipogon. Genetics 150: 899-909.

40. Yamamoto T, Taguchi SF, Ukai Y, Sasaki T, Yano M.
2001. Mapping quantitative trait loci for days-to-heading, and culm, panicle and internode lengths in a BC1F3 population using an elite rice variety, Koshihikari, as the recurrent parent. Breed. Sci. 51: 63-71.

41. Yoshida S, Ikegami M, Kuze J, Sawada K, Hashimoto Z, Ishii T, Nakamura C, Kamijima O. 2002. QTL analysis for plant and grain characters of sake-brewing rice using a doubled haploid population. Breed. Sci. 52: 309-317.

42. Zhuang JY, Lin HX, Lu J, Qian HR, Hittalnami S, Huang N, Zheng KL. 1997. Analysis of QTL X environment interaction for yield components and plant height in rice. Theor. Appl. Genet. 95: 799-808. 